\title{
On universal Free Choice items
}

\author{
Paula Menéndez-Benito
}

Published online: 19 March 2010

(C) The Author(s) 2010. This article is published with open access at Springerlink.com

\begin{abstract}
This paper deals with the interpretation and distribution of universal Free Choice (FC) items, such as English FC any or Spanish cualquiera. Crosslinguistically, universal FC items can be characterized as follows. First, they have a restricted distribution. Second, they express freedom of choice: the sentence You can take any card conveys the information that the addressee is free to pick whichever card she chooses. Under standard assumptions, the truth conditions of sentences like You can take any card are taken to be captured by formalizations in which a universal quantifier ranging over individuals has wide scope over the possibility modal. The crucial observation that informs the account in this paper is that this type of formalization cannot capture the freedom of choice component. I will argue that in order to derive the right interaction between possibility modals and FC items, we need to add an exclusiveness condition to the standard wide scope paraphrases. The same proposal that guarantees freedom of choice will automatically account for the distribution restrictions of FC items. The formal implementation of this proposal is cast in the Hamblin semantics proposed in Kratzer and Shimoyama (Indeterminate phrases: The view from Japanese, 2002).
\end{abstract}

Keywords Free Choice · Indefinites · Alternatives · Exhaustivity

\section{Introduction: universal Free Choice items}

Across languages, we find universal Free Choice (FC) items-items that express what Vendler (1967) dubbed 'Freedom of Choice' and that can be given a universal

P. Menéndez-Benito (ه)

Department of English Language and Literature, University of Göttingen,

37073 Göttingen, Germany

e-mail: Paula.Menendez-Benito@phil.uni-goettingen.de 
paraphrase. ${ }^{1}$ Both Spanish cualquiera and English any belong to this category. By uttering the Spanish sentence in (1a) or its English counterpart in (1b) I inform my addressee that all the cards are permitted possibilities for her; thus I grant her "the unrestricted liberty of individual choice" (Vendler 1967: 80). These sentences are often paraphrased as 'For every card $\mathrm{x}$ in this deck you can take $\mathrm{x}$.'

(1) a. Puedes coger cualquier carta de esta baraja.

'You can take any card from this deck.'

b. You can take any card from this deck.

Universal FC items have a restricted distribution. Crosslinguistically, they are licensed in possibility sentences (see (1) above) and ruled out in episodic sentences (as in (2)) and in necessity statements like (3). These items thus seem sensitive to some property of their environment. But in view of the data in (1) through (3) it is far from obvious what this property might be: looking at the contrast between (1) and (2) one might think that the relevant property is modality (that is, that universal FC items are 'modality-sensitive' elements). But as (3) shows, not any type of modal will do.

(2) a. *Juan cogió cualquiera de las cartas de esta baraja.

'Juan took-pfv. any of the cards from this deck.'

b. *John took any of the cards from this deck.

(3) a. *Juan tiene que coger cualquiera de las cartas de esta baraja.

'Juan must take any of the cards from this deck.'

b. *John must take any of the cards from this deck.

While universal FC items seem to involve quantification, they don't behave like 'textbook' quantifiers. As illustrated by the examples above, they have a puzzling distribution and they have obligatory wide scope with respect to possibility modals. An analysis of these items is thus likely to contribute insights into the properties of quantification in natural language. Much current research aims to provide such an analysis (see e.g., Aloni 2003, 2007a, b; Abrusán 2007a; Arregui 2006; Dayal 1998, 2004; Chierchia 2006; Farkas 2006; Giannakidou 2001; Giannakidou and Cheng 2006; Horn 2000, 2005; Jayez and Tovena 2005; Quer 1998, 2000; Sæbø 2001, among others). Many of these proposals share the assumption that the truth conditions of possibility sentences like (1) above can be captured by wide scope universal formalizations such as 'For every $\mathrm{x}$ such that $\mathrm{x}$ is a card in this deck, you may take x.' A number of different ways of deriving paraphrases that essentially boil down to this structure have been proposed in the literature (see, e.g., Aloni 2003, 2007a; Dayal 1998, 2004; Chierchia 2006; Sæbø 2001). The crucial observation that informs the account in this paper is that-surprisingly - this type of formalization

\footnotetext{
1 Until relatively recently the term 'Free Choice Item' has been reserved for items of the any-type, which have a universal interpretation. Kratzer and Shimoyama (2002) have shown that some existential indefinites (e.g., German irgendein) also have a FC component. Most of the FC literature now differentiates between Existential FC items (irgendein and its kin) and Universal (any-like) FC items.
} 
cannot capture the freedom of choice component. I will argue that in order to derive the right interaction between possibility modals and FC items we need to add an exclusiveness condition to the standard wide scope universal paraphrases. Once this proposal has been implemented, both the ungrammaticality of the FC items in (2) and (3) and their obligatory wide scope in (1) will fall out automatically.

The paper is organized as follows. Section 2 is devoted to capturing the FC effect. In Sect. 2.1 I argue that wide scope universal paraphrases do not guarantee freedom of choice. Section 2.2 shows how this problem can be overcome by adding an exclusiveness condition and Sect. 2.3 puts forward a compositional implementation of this idea, cast in Kratzer and Shimoyama's Hamblin semantics (Kratzer and Shimoyama 2002). Section 3 shows that the proposal developed in 2.3 accounts for the distributional restrictions of FC items exemplified above. In Sect. 4, I briefly discuss some of the questions raised by the proposal. Section 5 deals with necessity sentences that, unlike (3) above, license universal FC items (e.g., Any student must work hard). Section 6 discusses the repair strategy dubbed 'subtrigging' in LeGrand (1975). Finally, Sect. 7 presents some issues for further research.

\section{Accounting for the Free Choice effect}

\subsection{Wide scope universal quantification does not guarantee Free Choice}

One of the central questions of research on FC items of the any-type has been how to derive their universal flavor. Kadmon and Landman (1993) analyzed any as an indefinite that gets a universal-like interpretation in generic contexts. However, Dayal (1998) convincingly argued that FC any does not pattern with generic indefinites, and proposed instead that this item is a universal quantifier that ranges over possible individuals. On Sæb $\varnothing$ 's (2001) analysis, Scandinavian FC items also contribute a universal determiner as part of their meaning. A different view is put forward in Aloni (2003, 2007a), where the universal interpretation we see in sentences like Anyone may enter comes about because the possibility modal introduces universal quantification over propositions. Chierchia (2006) treats FC items as existential quantifiers and claims that their apparent universal force results from combining the existential assertion with a domain widening implicature (in the spirit of Kratzer and Shimoyama 2002). This list, while by no means exhaustive, illustrates the wide range of proposals that have been entertained in the literature.

While analyses differ widely with respect to the source of the universal interpretation, there is widespread agreement that the truth conditions of possibility sentences like (4) below ${ }^{2}$ correspond to formalizations in which a universal quantifier ranging over individuals has scope over the possibility modal. ${ }^{3}$ On this view, (4) would denote the proposition in (5) below.

\footnotetext{
${ }^{2}$ Unless otherwise indicated, the judgments reported here obtain both for cualquiera and FC any. For reasons of space, in Sects. 2 and 3 I will provide only Spanish examples.

3 Some exceptions are Giannakidou (2001) as well as Abrusán (2007a) and Aloni (2007b), both of whom build on Menéndez-Benito (2005).
} 
(4) Puedes coger cualquiera de las cartas del mazo.

'You can take any of the cards in the discard pile.'

(5) The proposition that is true in a world $w$ iff for every $\mathrm{x}$ such that $\mathrm{x}$ is a combination of cards in the discard pile, there is a world accessible from $\mathrm{w}$ in which you take $\mathrm{x} .^{4}$

Surprisingly, however, wide scope universal paraphrases yield wrong truth-conditions for sentences like (4). By adopting formalizations like (5) we would predict (4) to be true in situations where there is no complete freedom of choice. To see why, consider the following scenario.

\section{The Canasta scenario 5}

One of the rules of the card game Canasta is: When a player has two cards that match the top card of the discard pile, she has two options: (i) take all the cards in the discard pile and (ii) take no card from the discard pile (but take the top card of the regular pile instead). Those are her two only options.

Now, consider the sentence in (6). Is this sentence true in the scenario above?

(6) En Canasta, puedes coger cualquiera de las cartas del mazo cuando tienes dos cartas que son del mismo palo que la de arriba del mazo.

'In Canasta, you can take any of the cards in the discard pile when you have two cards that match its top card.'

No. Given the rules of Canasta, the sentence in (6) is clearly false (you do not have "unrestricted liberty"!). However, the formalization in (5) predicts (6) to be true in the Canasta scenario. Let us see why.

Suppose that you are playing Canasta and have two cards that match the top card of the discard pile. Assume further that the only cards left in the discard pile are the Queen of Hearts and the Ace of Spades. Then, there are two types of worlds that are permissible for you, namely:

(7) Type 1 worlds: worlds in which you take both the Queen and the Ace Type 2 worlds: worlds in which you take no card from the discard pile

Given the paraphrase in (5), the sentence in (8) will be true in the actual world, $\mathrm{w}_{0}$, if and only if the three conditions in (9) are satisfied.

(8) Puedes coger cualquiera de las cartas del mazo.

'You can take any of the cards in the discard pile.'

\footnotetext{
${ }^{4}$ Here, I am using the informal term 'combination of cards' to cover both individual cards and sums of cards (Link 1983).

${ }^{5}$ Many thanks to Angelika Kratzer and Florian Schwarz for long and extremely helpful discussions about the relevant scenarios.
} 
(9) (i) There is a world accessible from $w_{0}$ in which you take the Queen.

(ii) There is a world accessible from $\mathrm{w}_{0}$ in which you take the Ace.

(iii) There is a world accessible from $\mathrm{w}_{0}$ in which you take the Queen and the Ace.

These three conditions are indeed met in the situation described in (7), where (i) there are worlds accessible from $w_{0}$ in which you take the Queen, namely all the type 1 worlds; (ii) there are worlds accessible from $w_{0}$ in which you take the Ace, again all the type 1 worlds; and (iii) there are worlds accessible from $w_{0}$ in which you take the Queen and the Ace (the type 1 worlds, once more).

Standard wide scope paraphrases, then, predict possibility sentences like (8) to be true in a situation where there is no freedom of choice. The following scenario illustrates the same point.

\section{The competition scenario}

To enter a certain competition, you must answer at least three questions out of a list of four. You can choose which questions you answer.

Now, consider the sentence in (10).

(10) Para participar en la competición, puedes contestar cualquier combinación de esas preguntas.

'To enter the competition, you can answer any combination of those questions.'

This sentence is false in the above scenario: given the rules of the competition, you are not free to choose just two questions, for instance. However, the wide scope universal analysis predicts the sentence to be true.

Given this scenario, your deontic alternatives look as follows:

(11) Type 1 worlds: you answer questions 1, 2, 3

Type 2 worlds: you answer questions $1,3,4$

Type 3 worlds: you answer questions 1, 4, 2

Type 4 worlds: you answer questions 2, 3, 4

Type 5 worlds: you answer questions 1, 2, 3, 4

On the standard wide scope universal analysis, the relevant portion of (10) would denote the proposition in (12).

(12) The proposition that is true in a world $w$ iff for every $x$ such that $x$ is a combination of questions, there is a world accessible from $w$ in which you answer $\mathrm{x}$.

And the proposition in (12) is indeed true in our scenario, which satisfies the three conditions below. 
(i) There is an accessible world where you answer all the questions (all the Type 5 worlds).

(ii) For each combination $\mathrm{x}$ of three questions, there is an accessible world in which you answer $\mathrm{x}$ :

There is an accessible world in which you answer 1, 2, and 3 (e.g., Type 1 worlds)

There is an accessible world in which you answer 1, 3, and 4 (e.g., Type 2 worlds)

There is an accessible world in which you answer 1, 4, and 2 (e.g., Type 3 worlds)

There is an accessible world in which you answer 2, 3, and 4 (e.g., Type 4 worlds)

(iii) For each combination $\mathrm{x}$ of two questions, there is an accessible world in which you answer $\mathrm{x}$ :

There is an accessible world in which you answer 1 and 2 (e.g., Type 1 worlds)

There is an accessible world in which you answer 1 and 3

(e.g., Type 1 worlds)

There is an accessible world in which you answer 1 and 4 (e.g., Type 2 worlds)

... and so on for all the combinations of two cards.

The examples above show that a standard wide scope universal account yields wrong truth conditions for possibility sentences that contain cualquiera-it predicts them to be true in cases where freedom of choice is limited.

\subsection{The solution: exclusiveness}

As we have seen, the paraphrase in (14) does not correctly capture the truthconditions of (13) because it does not guarantee that for every card there is a distinct world in which you take that card. I contend that this problem can be overcome by adding an exclusiveness requirement to standard wide scope universal paraphrases. On this proposal, (13) will be assigned the denotation in (15).

(13) Puedes coger cualquiera de las cartas del mazo.

'You can take any of the cards in the discard pile.'

(14) The proposition that is true in a world $w$ iff for every $x$ such that $x$ is a combination of cards in the discard pile, there is a world accessible from $\mathrm{w}$ in which you take $\mathrm{x}$. 
(15) The proposition that is true in a world $w$ iff for every $\mathrm{x}$ such that $\mathrm{x}$ is a combination of cards in the discard pile, there is a world accessible from $\mathrm{w}$ in which you take $\mathrm{x}$ and no other cards that are not part of $x$.

This type of paraphrase gives us the desired Free Choice effect. To illustrate this, let us go back to the scenarios above.

\section{The Canasta scenario revisited}

According to the proposal in (15), the sentence in (13) will be true in $\mathrm{w}_{0}$ (still assuming that the Queen and the Ace are the only cards left in the pile) iff all three conditions in (16) below are satisfied:

(16) (i) There is a world accessible from $\mathrm{w}_{0}$ in which you take the Queen but not the Ace.

(ii) There is a world accessible from $\mathrm{w}_{0}$ in which you take the Ace but not the Queen.

(iii) There is a world accessible from $\mathrm{w}_{0}$ in which you take the Ace and the Queen.

The first two conditions are not met in the situation described in (7). Hence, (13) is correctly predicted to be false in the Canasta scenario.

The competition scenario revisited

The sentence in (10), repeated below as (17), will now be paraphrased as in (18).

(17) Para participar en la competición, puedes contestar cualquier combinación de esas preguntas.

'To enter the competition, you can answer any combination of those questions.'

(18) The proposition that is true in a world $w$ iff for every $x$ such that $x$ is a combination of those questions, there is a world accessible from $\mathrm{w}$ in which you answer $\mathrm{x}$ and no other questions that are not part of $x$.

Proposition (18) is false in the competition scenario. Take, for instance, the combination of questions 1 and 2: There is no accessible world in which you answer questions 1 and 2, and no other questions.

By adding the exclusiveness requirement, we have derived Vendler's insight: the essential feature of (items like) any is freedom of choice. The next step will be to introduce this requirement in a compositional fashion. The following section is devoted to this task.

\subsection{Implementing the solution}

In what follows, I will show that the Hamblin semantics for indefinites developed in Kratzer and Shimoyama (2002) allows us to introduce the exclusiveness condition 
in a principled way. ${ }^{6}$ I will start out by presenting the core features of Kratzer and Shimoyama's proposal (Sect. 2.3.1). Once the relevant background is in place, I will put forward my analysis of universal FC items (Sect. 2.3.2) and show how this analysis captures the idea informally sketched above (Sect. 2.3.3).

\subsubsection{Background: Kratzer and Shimoyama (2002)}

Kratzer and Shimoyama (2002) put forward a Hamblin semantics for indeterminate pronouns. In this system, all expressions denote sets. Most lexical items denote singleton sets containing their traditional denotations. For instance, the verb arrived denotes the singleton set containing the property 'arrived', as in (19).

$$
[[\text { arrived }]]^{\mathrm{w}, \mathrm{g}}=\left\{\lambda \mathrm{x} \lambda \mathrm{w}^{\prime}\left(\operatorname{arrived}^{\prime}(\mathrm{x})\left(\mathrm{w}^{\prime}\right)\right)\right\}
$$

Indeterminate pronouns and phrases denote sets of individual alternatives. For instance, the denotation of a man in a world $\mathrm{w}$ is the set of men in w, as below.

$$
[[\text { a man }]]^{\mathrm{w}, \mathrm{g}}=\left\{\mathrm{x}: \operatorname{man}^{\prime}(\mathrm{x})(\mathrm{w})\right\}=\{\text { Juan, Pedro, Carlos } \ldots\}
$$

Via pointwise functional application, ${ }^{7}$ the alternatives created by indeterminate phrases can expand, i.e., give rise to alternatives of a higher type: to combine the denotation of arrived with the denotation of a man, we apply the function in the denotation of arrived to each of the elements in the denotation of $a$ man. The result is the set of propositional alternatives in (21) — that is, the set of propositions \{ that Juan arrived, that Pedro arrived, that Carlos arrived... (and so on, for all the men in the world of evaluation).

$$
[[\text { a man arrived }]]^{\mathrm{w}, \mathrm{g}}=\left\{\mathrm{p}: \exists \mathrm{x}\left(\operatorname{man}^{\prime}(\mathrm{x})(\mathrm{w}) \& \mathrm{p}=\lambda \mathrm{w}^{\prime}\left(\operatorname{arrived}^{\prime}(\mathrm{x})\left(\mathrm{w}^{\prime}\right)\right)\right)\right\}
$$

The alternatives keep expanding until they meet an operator that selects them. The denotation of the sentence $A$ man arrived results from combining the set of propositions in (21) with the propositional operator [ $\exists]$ in (22), as in (23). This yields the proposition that is true just in case at least one alternative in (21) is true (i.e., the proposition that at least one man arrived).

(22) For any set of propositions $A,[\exists](A)=\{$ the proposition that is true in all worlds in which some proposition in $\mathrm{A}$ is true

(Kratzer and Shimoyama 2002, 6)

\footnotetext{
${ }^{6}$ In previous work, I explored an alternative way of introducing the exclusiveness requirement, which makes crucial use of Fox's (2002) Trace Conversion rule. However, this implementation commits us to the assumption that traces can trigger the introduction of a set of alternatives, which I take to be problematic. (It is not clear how alternatives would be introduced in the absence of focus.) See Menéndez-Benito (2005) for discussion.

7 Formally, Hamblin Functional Application is defined as follows:
}

(i) If $\alpha$ is a branching node with daughters $\beta$ and $\gamma$, and $[[\beta]]^{\mathrm{w}, \mathrm{g}} \subseteq \mathrm{D}_{\sigma}$ and $[[\gamma]]^{\mathrm{w}, \mathrm{g}} \subseteq \mathrm{D}_{<\sigma \tau>}$, then $[[\alpha]]^{\mathrm{w}, \mathrm{g}}=\left\{\mathrm{a} \in \mathrm{D}_{\tau}: \exists \mathrm{b} \exists \mathrm{c}\left[\mathrm{b} \in[[\beta]]^{\mathrm{w}, \mathrm{g}} \& \mathrm{c} \in[[\gamma]]^{\mathrm{w}, \mathrm{g}} \& \mathrm{a}=\mathrm{c}(\mathrm{b})\right]\right\}$. 


\section{$[\exists]\left([[\text { a man arrived }]]^{\mathrm{w}, \mathrm{g}}\right)$}

Other propositional operators in Kratzer and Shimoyama (2002) are:

(24) For any set of propositions A,

$[\forall](A)=\{$ the proposition that is true in all worlds in which every proposition in $\mathrm{A}$ is true $\}$

$[\mathrm{Neg}](\mathrm{A})=\{$ the proposition that is true in all worlds in which no

[Q] $(\mathrm{A})=\{\mathrm{A}\}^{8}$ proposition in $\mathrm{A}$ is true $\}$

Kratzer and Shimoyama draw a distinction between unselective and selective indeterminate pronouns: the alternatives generated by unselective indeterminate pronouns can be caught by any operator. A case in point is that of Japanese indeterminate pronouns, which can take on existential, universal, interrogative, negative polarity or FC readings depending on the operator they associate with. In contrast, other indeterminate pronouns are selective. For instance, German irgendein can only get existential readings. In the framework presented above, this amounts to saying that the alternatives generated by irgendein can only be operated on by [ $\exists]$. To characterize the relationship between selective indeterminates and the operators they associate with, Kratzer (2005) proposes that selective indeterminate phrases carry meaningless morphology that signals agreement with matching interpretable operators. ${ }^{9}$ On this view, existential indefinites like German irgendein would associate with [ $\exists]$, interrogative indefinites with [Q], and n-words in negative concord languages with [Neg].

Let us now see how the informal proposal in Sect. 2.3.1 can be implemented in the Kratzer and Shimoyama system.

\subsubsection{The proposal}

The analysis of universal FC items that I will pursue has two key components. First, I claim that universal FC items are universal indeterminate pronouns. As such, they introduce a set of alternatives, as in (25), and must agree with the $[\forall]$ propositional quantifier in (26). ${ }^{10}$

(25) $[[\text { cualquiera de las cartas del mazo }]]^{\mathrm{w}, \mathrm{g}}=\{$ The Queen, the Ace, the Queen+the Ace\}

\footnotetext{
8 This operator delivers Hamblin-style denotations (Hamblin 1973). See Kratzer and Shimoyama (2002) for the operator that delivers Groenendijk and Stokhof-type denotations (Groenendijk and Stokhof 1984).

9 Kratzer and Shimoyama (2002) consider a feature checking analysis instead.

${ }^{10}$ In the analysis of FC any put forward in Aloni (2002, 2007a) indefinite pronouns also introduce sets of propositional alternatives. On Aloni's account, however, quantification over these alternatives comes about in a different way than in Kratzer and Shimoyama's proposal. Aloni (2007b) presents a view closer to the one assumed here. Arregui (2006) also analyzes cualquiera as a Hamblin indefinite, but her proposal differs in several crucial ways from the one put forward here.
} 
(26) For any set of propositions $A,[\forall](A)=\{$ the proposition that is true in all worlds in which every proposition in $\mathrm{A}$ is true $\}$

(Kratzer and Shimoyama 2002, 6)

Existential indeterminates are by now well-documented crosslinguistically (irgendein and its $\mathrm{kin}^{11}$ ), and so are interrogative indeterminates (wh-words) and negative indeterminates (negative concord indefinites). Within the Kratzer and Shimoyama setup, the existence of universal indeterminates is in principle expected. If the propositional universal quantifier is in fact available in natural language, we expect there to be some indeterminates that must associate with it.

Second, I hypothesize that the propositional alternatives denoted by the smallest clausal component dominating the universal FC item are mapped into a set of mutually exclusive propositions. ${ }^{12}$ This is achieved by means of an exclusiveness operator akin to only, defined as in (27) below. ${ }^{13}$

$$
\begin{aligned}
& \operatorname{Excl}(\mathrm{A})=\{\lambda \mathrm{w}(\mathrm{p}(\mathrm{w}) \& \forall \mathrm{q}((\mathrm{q} \in \mathrm{A} \& \mathrm{q}(\mathrm{w})) \rightarrow(\mathrm{p} \Rightarrow \mathrm{q}))): \mathrm{p} \in \mathrm{A}\} \\
& \mathrm{p} \Rightarrow \mathrm{q}={ }_{\operatorname{def}} \forall \mathrm{w}(\mathrm{p}(\mathrm{w}) \rightarrow \mathrm{q}(\mathrm{w}))
\end{aligned}
$$

That is, if $\mathrm{A}$ is a set of propositions, we get $\operatorname{Excl}$ (A) by mapping each proposition $\mathrm{p}$ in $\mathrm{A}$ into the proposition that is true in a world $\mathrm{w}$ iff $\mathrm{p}$ is true in $\mathrm{w}$ and no other proposition in A is true in w, unless it is logically implied by p. For instance, Excl will map the set of propositions in (28) into the set of mutually exclusive propositions in (29).

$$
\begin{aligned}
\mathrm{A}= & \{\text { that Juan took the Queen, that Juan took the Ace, that Juan took } \\
& \text { the Queen and the Ace }\}
\end{aligned}
$$

$$
\begin{aligned}
\operatorname{Excl}(\mathrm{A})= & \{\text { that Juan took the Queen but not the Ace, } \\
& \text { that Juan took the Ace but not the Queen, } \\
& \text { that Juan took the Queen and the Ace }\}
\end{aligned}
$$

As we will see, the interaction between the two components above will not only derive the FC effect, but also go a long way toward accounting for the distributional properties of FC items.

\subsubsection{Putting the pieces together}

Let us first see how this proposal accounts for the truth conditions of possibility sentences such as (30) below.

\footnotetext{
11 See Kratzer's (2005) argument for existential concord.

12 Farkas (2006) also argues that the alternatives that are relevant for the interpretation of FC items are mutually exclusive. A comparison between her proposal and mine is beyond the scope of this paper.

13 Several authors have posited the existence of a covert operator akin to only (see, e.g., Chierchia 2006; Fox 2006, and references therein).
} 
(30) Juan puede coger cualquiera de las cartas del mazo.

'Juan can take any of the cards in the discard pile.'

The sentence in (30) will be assigned the LF in (31): I hypothesize that Excl sits right above the first node that denotes a set of propositional alternatives, i.e., the constituent that I have labeled $\mathrm{IP}_{1}$. (Motivating the distribution of Excl turns out to be not an easy matter. I will discuss this issue in Sect. 4. As for why $[\forall]$ is above the possibility modal, see also Sect. 4.)

(31) $[\forall$ [IP2 puede [Excl [IP1 Juan coger cualquiera de las cartas del mazo]]]]

For simplicity, let us assume again that the only two cards left in the discard pile are the Queen of Hearts and the Ace of Spades. Then, following Link (1983, 1991), las cartas del mazo ('the cards in the discard pile') will denote the plural individual 'the Queen of Hearts+the Ace of Spades'. The partitive complement de las cartas del mazo ('of the cards in the discard pile') will denote the property of individuals that are part of that plural individual (Link 1991). The denotation of cualquiera de las cartas del mazo will then be the set of individuals that satisfy the property denoted by de las cartas del mazo-that is, (32) below.

(32) $[[\text { cualquiera de las cartas del mazo }]]^{\mathrm{w}, \mathrm{g}}=\{$ The Queen, the Ace, the Queen+the Ace\}

As we have seen, in the Kratzer and Shimoyama system, lexical items that do not introduce alternatives denote singleton sets containing their traditional denotations. So, we have:

$$
\begin{aligned}
& {[[\text { coger }]]^{\mathrm{w}, \mathrm{g}}=\left\{\lambda \mathrm{x} \lambda \mathrm{y} \lambda \mathrm{w}^{\prime}\left(\operatorname{take}^{\prime}(\mathrm{x})(\mathrm{y})\left(\mathrm{w}^{\prime}\right)\right)\right\}} \\
& {[[\text { Juan }]]^{\mathrm{w}, \mathrm{g}}=\{\text { Juan }\}}
\end{aligned}
$$

Combining the denotation of the verb with the set of individual alternatives in (32) via pointwise functional application we get the set of alternatives below:

$\left\{\lambda y \lambda \mathrm{w}^{\prime}\left(\operatorname{take}^{\prime}(\right.\right.$ the Queen $\left.)(\mathrm{y})\left(\mathrm{w}^{\prime}\right)\right), \lambda \mathrm{y} \lambda \mathrm{w}^{\prime}\left(\right.$ take $^{\prime}($ the Ace $\left.)(\mathrm{y})\left(\mathrm{w}^{\prime}\right)\right)$, $\lambda y \lambda \mathrm{w}^{\prime}\left(\right.$ take' $^{\prime}$ (the Queen+the Ace $\left.\left.)(\mathrm{y})\left(\mathrm{w}^{\prime}\right)\right)\right\}$

Applying (35) pointwise to the denotation of Juan yields the set of propositional alternatives in (36) - that is, \{that Juan takes the Queen, that Juan takes the Ace, that Juan takes the Queen and the Ace .

$$
\begin{aligned}
{\left[\left[I P_{1}\right]\right]^{\mathrm{w}, \mathrm{g}}=} & \left\{\lambda \mathrm{w}^{\prime}\left(\operatorname{take}^{\prime}(\text { the Queen })(\operatorname{Juan})\left(\mathrm{w}^{\prime}\right)\right), \lambda \mathrm{w}^{\prime}\left(\operatorname{take}^{\prime}(\text { the Ace })(\mathrm{Juan})\left(\mathrm{w}^{\prime}\right)\right),\right. \\
& \left.\lambda \mathrm{w}^{\prime}\left(\operatorname{take}^{\prime}(\text { the Queen+the Ace })(\operatorname{Juan})\left(\mathrm{w}^{\prime}\right)\right)\right\}
\end{aligned}
$$


Applying Excl to (36), we get:

(37) Ithat Juan takes the Queen but not the Ace, that Juan takes the Ace but not the Queen, that Juan takes the Queen and the Ace\}

I will assume that the possibility modal has the denotation in (38) (see below for discussion). Combining (38) with (37), we obtain the set of alternatives in (39).

$$
[[\text { poder }]]^{\mathrm{w}, \mathrm{g}}=\left\{\lambda \mathrm{p} \lambda \mathrm{w}^{\prime} \exists \mathrm{w}^{\prime \prime}\left(\operatorname{acc}\left(\mathrm{w}^{\prime}\right)\left(\mathrm{w}^{\prime \prime}\right) \& \mathrm{p}\left(\mathrm{w}^{\prime \prime}\right)\right)\right\}
$$

$\left[\left[I P_{2}\right]\right]^{\mathrm{w}, \mathrm{g}}=$

\{that there is an accessible world in which Juan takes the Queen but not the Ace,

that there is an accessible world in which Juan takes the Ace but not the Queen,

that there is an accessible world in which Juan takes the Queen and the Ace

And, finally, applying $[\forall]$ to the set of propositions in (39), we get the Free Choice effect: (30) will be true in a world $w$ iff

(i) there is a world accessible from $\mathrm{w}$ in which Juan takes the Queen but not the Ace and

(ii) there is a world accessible from $\mathrm{w}$ in which Juan takes the Ace but not the Queen, and

(iii) there is a world accessible from w in which Juan takes the Ace and the Queen.

This, of course, is the Free Choice effect that we were trying to derive. Now the sentence in (30) comes out false in the Canasta scenario, in accordance with our intuitions.

As we have seen, the analysis proposed above derives the Free Choice effect in possibility sentences. Note that, in order to achieve this result, we need to assume that modals let the alternatives project up the tree, as in (38). This type of denotation crucially differs from the one assumed in Kratzer and Shimoyama (2002). Following Heim 1982, Kratzer and Shimoyama take the scope of modal operators to be existentially closed. In their framework, this means that the existential propositional quantifier stops the expansion of any alternatives that are introduced below the modal. If we assumed this, we would predict sentences like (30) to be ungrammatical since, as illustrated schematically in (40) below, the existential propositional quantifier would create an intervention effect. ${ }^{14}$

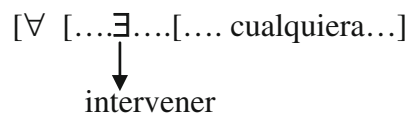

As an anonymous reviewer points out, this makes a general prediction, namely that the only existential quantifiers that will license universal FC items are those that

\footnotetext{
${ }^{14}$ For discussion of intervention effects, see Kratzer and Shimoyama (2002).
} 
combine with their complement by pointwise functional application. Further research is needed to explore the consequences of this prediction.

\section{Deriving the distribution of Free Choice items}

The very same proposal that derives the right interaction between possibility modals and universal FC items (by guaranteeing freedom of choice) explains the ungrammaticality of universal FC items in episodic and necessity sentences, on the grounds that they have impossible truth conditions. This explanation relies on Gajewski (2002), who argues that there is a formal principle of grammar that rules out sentences that are contradictory in virtue of their logical structure.

Let us start by computing the denotation of the LF in (42), which corresponds to the episodic sentence in (41). (For simplicity's sake, I am not spelling out the contribution of tense and aspect.)

(41) *Juan cogió cualquiera de las cartas del mazo.

'Juan took-pfv. any of the cards in the discard pile.'

\section{[ $\forall\left[\mathrm{Excl}_{\text {IP1 }}[\right.$ Juan cogió cualquiera de las cartas del mazo]]]}

The constituent labeled $\mathrm{IP}_{1}$ denotes the set of propositional alternatives in (43).

$$
\begin{aligned}
{\left[\left[I P_{1}\right]\right]^{\mathrm{w}, \mathrm{g}}=} & \{\text { that Juan took the Queen, that Juan took the Ace, } \\
& \text { that Juan took the Queen and the Ace }\}
\end{aligned}
$$

Applying Excl to (43) we get the set of mutually exclusive propositions in (44).

(44) \{that Juan took the Queen but not the Ace, that Juan took the Ace but not the Queen, that Juan took the Queen and the Ace\}

And the result of combining (44) with $[\forall]$ is the singleton set containing the proposition that is true in a world w iff every proposition in (44) is true in w. Since all these propositions cannot be true in the same world, (41) is a contradiction! This, I contend, accounts for its ungrammaticality (see below for discussion of this line of explanation).

Let us now turn to the LF in (45), which corresponds to the necessity sentence in (46).

(45) $\quad\left[\forall\left[\right.\right.$ tiene que[Excl ${ }_{\text {IP1 }}$ [Juan coger cualquiera de las cartas del mazo]]]]

(46) *Juan tiene que coger cualquiera de las cartas del mazo. 'Juan must take any of the cards in the discard pile.'

Applying Excl to the denotation of $I P_{1}$ yields the set of mutually incompatible propositions in (47). 
(47) \{that Juan takes the Queen but not the Ace, that Juan takes the Ace but not the Queen that Juan takes the Queen and the Ace\}

Combining the denotation of the modal in (48) with (47), we will get (49).

$[[\text { tener que }]]^{\mathrm{w}, \mathrm{g}}=\left\{\lambda \mathrm{p} \lambda \mathrm{w}^{\prime} \forall \mathrm{w}^{\prime \prime}\left(\operatorname{acc}\left(\mathrm{w}^{\prime}\right)\left(\mathrm{w}^{\prime \prime}\right) \rightarrow \mathrm{p}\left(\mathrm{w}^{\prime \prime}\right)\right)\right\}$

(49) \{that in all accessible worlds Juan takes the Queen but not the Ace, that in all accessible worlds Juan takes the Ace but not the Queen, that in all accessible worlds Juan takes the Queen and the Ace\}

When we apply $[\forall]$ to (49), we get (the singleton set containing) the proposition that is true in a world $w$ iff all the propositions in (49) are true in w. But there is no world in which all the propositions in (49) can be true! ${ }^{15}$ Just as in the case of episodic sentences, universal quantification over a set of mutually exclusive propositions yields a contradiction.

The analysis in Sect. 2 also provides an explanation of why [ $\forall]$ must have wide scope with respect to possibility modals. Suppose that the sentence in (50) had the LF in (51), where $[\forall]$ is below the modal.

(50) Juan puede coger cualquiera de las cartas del mazo.

(51) [puede[ $\forall[$ Excl [IP1 Juan coger cualquiera de las cartas del mazo]]]]

Combining $[\forall]$ with the set of mutually exclusive propositions denoted by [Excl $\left.\left[I P_{1}\right]\right]$ (see above), we get the singleton set containing the proposition that is true in a world $\mathrm{w}$ iff all the propositions in (52) below are true in $\mathrm{w}$. This is a contradiction: there is no world in which all these propositions are true.

(52) \{that Juan takes the Queen but not the Ace, that Juan takes the Ace but not the Queen, that Juan takes the Queen and the Ace

Combining this contradictory proposition with the possibility modal yields a contradiction again, namely (the singleton set containing) the proposition that is true in a world $\mathrm{w}$ iff there is a world accessible from $\mathrm{w}$ where all the propositions in (52) are true. We can then rule out the configuration in (51) on the grounds that it expresses a contradiction. In this way, the unavailability of narrow scope universal readings also falls out automatically from the architecture of the system.

I have claimed that episodic sentences like (41), necessity sentences like (46) and the narrow scope configuration in (51) are ruled out because they have contradictory truth conditions. The idea that sentences can be rendered ungrammatical because they express contradictions (or tautologies) has been proposed in connection with

\footnotetext{
15 An anonymous reviewer points out that, strictly speaking, all the propositions in (49) can be true in a world $\mathrm{w}$ if no worlds are accessible from it. I take it that this kind of accessibility relation is not relevant for modal quantification in natural language: quantifiers in natural language generally presuppose that their domain is not empty.
} 
a number of constructions (see, e.g., Dowty 1979; Barwise and Cooper 1981; Chierchia 1984; von Fintel 1993; Fox and Hackl 2006; Gajewski 2008a, b; Abrusán 2007b, 2008). As an illustration, take von Fintel's (1993) account of exceptive constructions. Exceptive phrases can combine with universal quantifiers but not with existential quantifiers, as shown by (53) and (54) below. In von Fintel's analysis, examples like (53) are ruled out because the interaction of but with existential quantifiers yields a contradiction. Given the semantics for but that von Fintel proposes, (53) below entails, on the one hand, that it is not the case that a man arrived and, on the other hand, that it is the case that a man who is not John arrived. The conjunction of these two entailments is of course a contradiction. In contrast, the acceptable sentence (54) triggers the entailments that it is not true that every man arrived and that every man who is not John arrived, which can be conjoined without contradiction. ${ }^{16}$

\section{*Some man but John arrived.}

Every boy but John arrived.

This line of analysis has proved rather fruitful in a number of other domains, such as durational phrases (Dowty 1979), existential sentences (Barwise and Cooper 1981), degree constructions (Fox and Hackl 2006), negative islands in comparatives (Gajewski 2008a), and weak islands (Abrusán 2007b, 2008). However, it has to face an obvious objection, namely that some sentences that express contradictions (or tautologies) are perfectly grammatical. For instance:

\section{(55) Every woman is a woman.}

(56) Some male is female.

(57) John is smoking and John is not smoking.

Gajewski (2002) puts this type of analysis on more solid grounds by claiming that there is a fundamental distinction between different types of contradictions/tautologies. ${ }^{17} \mathrm{He}$ argues that there is a formal principle of grammar that rules out contradictory and tautological sentences and that this principle applies at a level of representation (which he dubs the 'logical skeleton' of the sentence) that is underspecified with respect to the content of non-logical words. ${ }^{18}$ The logical skeleton of a sentence is derived from the sentence's LF by (i) identifying the maximal constituents containing no logical words, and (ii) replacing each such constituent with a distinct variable of the appropriate type. On Gajewski's account, a sentence is ungrammatical whenever its logical skeleton contains a constituent that is false (or true) under every variable assignment.

\footnotetext{
${ }^{16}$ Gajewski (2008b) extends von Fintel's account to other, more complex cases.

17 See Chierchia (1984) for another proposal in the same spirit.

18 On Gajewski's proposal, logical words are characterized by being permutation-invariant, as defined in van Benthem (1989).
} 
To briefly illustrate Gajewski's proposal, ${ }^{19}$ let us examine how it differentiates between the ungrammatical contradiction in (53) and the grammatical contradiction in (56) (see discussion in Gajewski 2002).

Consider the LF corresponding to (53), given in (58a) below. By replacing each non-logical element with a distinct variable of the appropriate type, we get the logical skeleton in (58b). Given von Fintel's analysis of but, (58) comes out as false under every variable assignment and, therefore, (53) is correctly predicted to be ungrammatical. Let us now turn to the grammatical sentence in (56). From its LF, (59a), we derive the logical skeleton in (59b). This representation will be assigned the value False under some variable assignments (e.g., the one that maps $v_{1}$ to the property of being male and $v_{2}$ to the property of being female) and the value True under others (say, the assignment that maps $\mathrm{v}_{1}$ to the property of being a boy and $\mathrm{v}_{2}$ to the property of being from Spain). Thus, as desired, the sentence in (56) is not predicted to be ungrammatical.

$$
\begin{aligned}
& \text { a. [[some [man [but John]]] arrived] } \\
& \text { b. } \quad\left[\left[\text { some }\left[\mathrm{v}_{1},<\mathrm{e}, \mathrm{t}>\left[\text { but } \mathrm{v}_{2},<\mathrm{e}, \mathrm{t}>\right]\right]\right] \mathrm{v}_{3},<\mathrm{e}, \mathrm{t}>\right] \\
& \text { a. [[some [male }]] \text { is [female }]] \\
& \text { b. } \left.\left.\quad\left[\left[\text { some }\left[\mathrm{v}_{1},<\mathrm{e}, \mathrm{t}\right\rangle\right]\right]\left[\mathrm{v}_{2},<\mathrm{e}, \mathrm{t}\right\rangle\right]\right]
\end{aligned}
$$

For this proposal to apply to the cases we are investigating here, we would need to assume that modals, aspect, Excl, universal FC items, and $[\forall]$ all belong to the set of logical words. Granting this, the LF corresponding to the sentence in (60), namely (61), would yield the logical skeleton in (62) (I am leaving out type subscripts, to improve readability). On the analysis proposed here, (62) will come out as false on every assignment of values to its free variables. If Gajewski is on the right track, this should be enough to explain the ungrammaticality of (60). The same rationale applies to the other ungrammatical cases we have considered.

(60) *John must take any card.

(61) $\quad[\forall[$ must $[$ Exh[John [take [any card $]]]]]]$

$\left[\forall\left[\operatorname{must}\left[\operatorname{Exh}\left[\mathrm{v}_{1}\left[\mathrm{v}_{2}\left[\right.\right.\right.\right.\right.\right.$ any $\left.\left.\left.\left.\left.\left.\mathrm{v}_{3}\right]\right]\right]\right]\right]\right]$

Let us take stock. I have shown that a standard wide scope universal account of universal FC items fails to capture the FC effect. We have seen that this problem can be overcome by adding an exclusiveness condition to the semantic representation. In order to implement this idea, I have claimed that (i) universal FC items are universal indeterminate pronouns and (ii) the propositional alternatives

\footnotetext{
19 For recent applications of Gajewski's proposal see Fox and Hackl (2006), Abrusán (2007b, 2008), and Gajewski (2008a). Gajewski (2009) discusses and further elaborates the ideas explored in Gajewski (2002).
} 
they introduce are mapped into a set of mutually exclusive propositions. The interaction of these two components accounts for the FC effect, predicts universal ${ }^{20}$ FC items to be ruled out in episodic and necessity sentences and explains the obligatory wide scope of the universal quantifier in possibility sentences.

The next section briefly addresses a couple of questions raised by the proposal above: (i) What is the nature of the universal propositional quantifier? (ii) What explains the distribution of Excl?

\section{Interim questions}

\subsection{The status of $[\forall]$}

Kratzer and Shimoyama suggest in passing that the operators indeterminate pronouns associate with may be contributed by inflectional categories "like 'episodic' or 'generic aspect', inflectional negation and wh-complementizers" (Kratzer and Shimoyama 2002, 26). On this view, the universal propositional quantifier would most likely be introduced by generic (imperfective) aspect. ${ }^{21}$ If this were the case, cualquiera would be ruled out in episodic sentences like (63) simply because aspectual morphology does not supply a $[\forall]$ operator.

\section{*Juan cogió cualquiera de las cartas del mazo. \\ 'Juan took-pfv. any of the cards in the discard pile.'}

However, there is ample evidence that generic morphology is not the source of the propositional universal quantifier. As Dayal (1998) notes for FC any, universal FC items can occur in sentences that do not involve verbal genericity. Consider, for instance, the example in (64). While any is licensed in (64a), the indefinite in (64b) cannot get a generic interpretation.

\footnotetext{
${ }^{20}$ As an anonymous reviewer notes, there are items, like German irgendein, which convey a Free Choice effect, but whose distribution differs from that of cualquiera or FC any (see, e.g., Kratzer and Shimoyama 2002, Aloni and van Rooij 2007; Chierchia 2006, a.o.). In particular, these items are good in episodic and necessity sentences, as the following examples illustrate for irgendein.
}

(ii) Mary musste irgendeinen Mann heiraten.

Mary had-to irgend-one man marry

(Kratzer and Shimoyama 2002, 10)

(iii) Irgendjemand hat angerufen. irgend-one has called

(Haspelmath 1997, 47).

Kratzer and Shimoyama (2002) argue that irgendein is an existential indeterminate pronoun (that is, an indeterminate pronoun that must agree with an alternative-selecting existential quantifier) and that the FC effect it triggers is a domain-widening implicature. On this view, the observed differences in distribution between cualquiera and irgendein are expected. For instance, on the narrow scope reading of irgendein, (ii) asserts that in all accessible worlds, there is a man that Mary marries, and implicates that for every man in the domain there is a distinct world where Mary marries that man. Unlike in the corresponding sentences with cualquiera, no contradiction arises, and irgendein is licensed. Different paths to Free Choice, then, may lead to different distributional properties.

21 For the connection between imperfective aspect and universal quantification see, e.g., Bonomi (1997). 
(64) a. You may pick any flower.

(Dayal 1998, 435)

b. You may pick a flower.

(Dayal 1998, 439)

How is $[\forall]$ introduced into the representation, then? As anticipated by the discussion in Sect. 3, I would like to suggest that $[\forall]$ is freely inserted, up to interpretability. ${ }^{22}$ According to this hypothesis, $[\forall]$ can be inserted in any place in the structure in which it (i) can agree with a universal FC item, (ii) can operate over a set of propositional alternatives, (iii) does not produce a fatal contradiction, and (iv) does not block agreement between another indeterminate and its corresponding matching operator (i.e., does not create an intervention effect). In cases like (63) then, cualquiera has no chance of survival: there is no way of introducing $[\forall]$ that would not give rise to a contradiction, and hence, the selectional requirement of cualquiera cannot be satisfied.

\subsection{The distribution of Excl}

We have seen that assuming that propositional alternatives get exclusified has a number of welcome consequences. But what introduces the Excl operator into the representation? Answering this question turns out not to be an easy task.

One possibility might be to try to tie exclusiveness to the lexical entry of items like cualquiera by proposing, e.g., that these items must agree with Excl. This view would square well with the account in Lee (2005), according to which the focus particle man in Korean signals agreement with a null only operator. However, hardwiring exclusification into the semantics of universal FC items would yield wrong results: as we will see in Sect. 5, there are some sentences with universal FC items that do not involve exclusiveness. What to do then? In her 2005 LSA lectures, Angelika Kratzer put forward the working hypothesis that propositional alternatives are always exclusified. ${ }^{23}$ On this view, Excl would apply as soon as possible after each introduction of an indeterminate (where 'as soon as possible' means 'as soon as we obtain propositional alternatives'). But this leaves us with the question of where this requirement comes from.

Perhaps the introduction of Excl is related to a general condition on alternatives, e.g., that they must be non-overlapping (see discussion in Zimmermann 2001; Simons 2005). If this were the case, we would expect Excl to be introduced at every point where we get propositional alternatives (i.e., at every clausal point). But, as Danny Fox (p.c.) has pointed out to me, this move would have disastrous consequences, namely that we would predict possibility sentences to be contradictory. The sentence in (65), for instance, would have the LF in (66), which has contradictory truth conditions (since the universal quantifier at the top of the clause ranges over a set of mutually exclusive propositions).

\footnotetext{
22 This possibility was suggested to me by Angelika Kratzer (p.c.).

${ }^{23}$ LSA lecture, MIT, July 19, 2005.
} 
(65) John may take any of these cards.

(66) $[\forall[$ Excl [may [Excl [John takes any of these cards $]]]]$

This shows that we can only have exclusification at the lowest point possible. But what motivates the introduction of Excl at precisely this place in the structure is still an open question, which I will have to leave unanswered here.

\section{More on necessity sentences}

The proposal that I have put forward rules out FC items in necessity sentences across-the-board, correctly predicting the ungrammaticality of examples like (67).

(67) *Juan tiene que coger cualquiera de estas cartas.

'Juan must take any of these cards.'

There are, however, necessity sentences that do license FC items, as the examples below illustrate.

(68) a. Cualquier estudiante debe trabajar duro.

'Any student must work hard.'

b. Any student must work hard.

(Dayal 1998, 435)

(69) a. Cualquier coche tiene que tener cinturón de seguridad 'Any car must have a security belt.'

b. Any car must have security belts.

(Aloni 2007a, 83)

This section is devoted to discussing this type of examples. Following work by Maria Aloni (Aloni 2003, 2007a), I will show how the proposal above can be modified so as to accommodate these problematic cases.

\subsection{Necessity sentences: the role of genericity}

We have just seen that, while universal FC items are ruled out in necessity sentences such as (67) above, there are some necessity sentences that allow these items. The example in (70), from Aloni $(2003,2007 a)$, is a case in point. Aloni notes that the plain indefinite in (71), which occurs in the same context as any in (70), can have a generic reading, and argues that sentences like (70) involve genericity.

(70) Any car must have security belts.

(Aloni 2007a, 83)

(71) A car must have security belts.

(Aloni 2007a, 83)

Following the discussion in Aloni (2003, 2007a), we can formulate the following generalization: 
(72) In necessity sentences, universal FC items are licensed only if a plain indefinite in the same position can get a generic interpretation.

The examples in (73) through (76), from Dayal (1998), support (72). The indefinites in (73a) and (74a) can be given a generic interpretation: (73a) may be understood as a generalization over students; (74a) as a generalization over soldiers. Replacing these indefinites with FC any yields the acceptable sentences (73b) and (74b). In contrast, the indefinites in (75a) and (76a) can only be interpreted existentially: (75a) cannot be interpreted as a generalization over flowers, nor can (76a) be interpreted as a generalization over pilots. In this case, replacing the indefinites with FC any, as in the corresponding (b)-examples, results in ungrammaticality. (The same judgments obtain for the corresponding Spanish sentences.)

(73) a. A student must work hard.

b. Any student must work hard.

(74) a. A soldier should be prepared to die for her country.

b. Any soldier should be prepared to die for her country.

(75) a. You must pick a flower.

b. *You must pick any flower.

(76) a. A pilot must be flying this plane.

b. *Any pilot must be flying this plane. (Dayal 1998, 435-438)

This correlation between the availability of generic interpretations for plain indefinites and the acceptability of FC items is exactly what Kadmon and Landman's (1993) analysis would lead us to expect. According to these authors, any is an indefinite with some special properties (widening, strengthening). The universal-like interpretation of FC any comes about via the same operator responsible for the generic reading of ordinary indefinites. Thus, Kadmon and Landman predict FC any to appear in precisely the same environments where ordinary indefinites can be interpreted generically. However, Dayal (1998) has shown that this prediction is not borne out. As we saw in Sect. 4, FC items are acceptable in possibility sentences regardless of whether an indefinite could have a generic interpretation in the same context. This is illustrated by (64), repeated below as (77). (See Dayal 1998 for more examples and for other arguments against Kadmon and Landman's account.)

\footnotetext{
a. You may pick any flower.

b. You may pick a flower.
}

(Dayal 1998, 435)

(Dayal 1998, 439)

Aloni (2003, 2007a) puts forward what we could dub a 'hybrid account'. In her proposal, modals introduce quantification over sets of propositional alternatives, as well as quantification over worlds. Possibility modals involve universal quantification over alternatives and existential quantification over worlds; necessity modals, existential quantification over alternatives and universal quantification over worlds. 
In combination with the semantics she proposes for FC any, this derives wide scope universal readings for possibility sentences and ungrammaticality for necessity sentences. To account for necessity sentences that do allow any, Aloni proposes that in those cases it is the generic operator that acts as a licensor, as Kadmon and Landman would have it. In her 2007a article, she tentatively suggests that all FC licensing operators might be universal quantifiers over sets of propositional alternatives. On this view, the generic operator would involve universal quantification over both propositional alternatives and worlds.

In what follows, I will adopt Aloni's claim that in necessity sentences like (70), (73b), or (74b), the FC item is licensed by the generic operator. I believe that this proposal can be quite naturally implemented in the account developed in Sects. 2 and 3. On this account, universal FC items are universal indeterminate pronouns, which must associate with a universal quantifier ranging over propositional alternatives. In the framework I am adopting here, the generic operator can be construed as a universal quantifier over individual alternatives, as in (78), which corresponds to the universal generalized quantifier in Kratzer and Shimoyama (Kratzer and Shimoyama 2002, 8).

$$
\begin{aligned}
& \text { For }[[\alpha]]^{\mathrm{w}, \mathrm{g}} \subseteq \mathrm{D}_{\mathrm{e}}: \\
& {[[G E N \alpha]]^{\mathrm{w}, \mathrm{g}}=\left\{\lambda \mathrm{P} \lambda \mathrm{w}^{\prime}\left(\forall \mathrm{a}\left(\mathrm{a} \in[[\alpha]]^{\mathrm{w}, \mathrm{g}} \rightarrow \mathrm{P}(\mathrm{a})\left(\mathrm{w}^{\prime}\right)=1\right)\right)\right\}}
\end{aligned}
$$

Of course, this cannot be the whole story! We know that generic quantification is not universal quantification: A student must work hard, on its generic reading, does not mean the same as Every student works hard (see, e.g., Krifka et al. 1995 and references therein). The semantics of the generic operator is a very intricate topic that I will not be able to address here. As we will see, the only crucial point for current purposes is that this operator ranges over sets of individual alternatives. In what follows, I will work with the denotation in (78), for simplicity's sake.

It seems reasonable to assume that the quantifier in (78) can also satisfy the selectional requirements of a universal indeterminate. Let us then propose that universal indeterminate pronouns have two interpretational possibilities:

(i) agreement with the universal quantifier over propositions, as in Sect. 2;

(ii) agreement with the generic operator, construed as a universal quantifier over individual alternatives.

If we take the route in (i), the semantic composition will proceed as described in Sects. 2 and 3: The FC item will stay in situ, and the individual alternatives it introduces will expand and give rise to propositional alternatives, which will then be exclusified. If we take the route in (ii) instead, the FC item will have to move to a position where it can combine with GEN, as in (79) below. (I am assuming that movement triggers the insertion of a binder index right below the moved element, as in Heim and Kratzer 1998.)

(79) a. Any student must work hard.

b. [[GEN [any student]] [IP21 [IP1 must [ $\mathrm{t}_{1}$ work hard]]]] 
Applying GEN to the set of individual alternatives denoted by any student yields the function in (80). In this computation, the individual alternatives contributed by the FC item are 'absorbed' by the generic operator. As a consequence, no propositional alternatives are generated and, hence, exclusiveness does not come into play.

$$
\left\{\lambda \mathrm{P} \lambda \mathrm{w}^{\prime}\left(\forall \mathrm{x}\left(\text { student }^{\prime}(\mathrm{x})\left(\mathrm{w}^{\prime}\right) \rightarrow \mathrm{P}(\mathrm{x})\left(\mathrm{w}^{\prime}\right)\right)\right)\right\}
$$

The modified proposal above predicts that the only way for a universal FC item to survive in a necessity sentence is to agree with the generic operator. In necessity sentences, association with the propositional quantifier yields a contradiction. In contrast, no contradiction will arise when the FC item associates with the generic operator. For instance, the sentence in (79) will denote the (singleton set containing the) non-contradictory proposition in $(81) .^{24}$

$$
\left\{\lambda \mathrm{w}^{\prime}\left(\forall \mathrm{x}\left(\text { student }^{\prime}(\mathrm{x})\left(\mathrm{w}^{\prime}\right) \rightarrow \forall \mathrm{w}^{\prime}\left(\operatorname{acc}\left(\mathrm{w}^{\prime}\right)\left(\mathrm{w}^{\prime \prime}\right) \rightarrow \text { work-hard }(\mathrm{x})\left(\mathrm{w}^{\prime \prime}\right)\right)\right)\right\}\right.
$$

Note that, given the assumptions I am making here, it is crucial that the generic operator quantifies over individual alternatives, as in (78), rather than over propositional alternatives, as suggested by Aloni (2007a). In cases like You must take any of these cards, we derive a contradiction because we universally quantify over a set of mutually exclusive propositions. In cases like (70), quantification over individual alternatives stops alternative expansion and blocks the creation of propositional alternatives, thereby eliminating the source of the contradiction.

Since we are taking universal FC items to be indefinites, we expect them to be able to combine with the generic operator exactly in the same contexts in which plain indefinites can do so. This accounts for the generalization in (72), repeated below as (82).

(82) In necessity sentences, universal FC items are licensed only if a plain indefinite in the same position can get a generic interpretation.

Before closing this section, there is another set of data that we need to consider. Up till now, we have looked only at sentences where the universal FC item was in subject position. These cases clearly support the generalization in (82). When we turn to object cases, judgments become somewhat murkier. Consider, for instance, the examples in (83) and (84).

(83) a. Tienes que contestar cualquier pregunta.

'You must answer any question.'

b. You must answer any question.

${ }^{24}$ In order to compute the denotation of the constituent that I have labeled $\mathrm{IP}_{2}$, we need to use Kratzer and Shimoyama's Predicate Abstraction rule:

(iv) If $\alpha$ is a branching node whose daughters are an index $i$ and $\beta$, where $[[\beta]]^{\mathrm{w}, \mathrm{g}} \subseteq \mathrm{D}_{\sigma}$, then $[[\alpha]]^{\mathrm{w}, \mathrm{g}}=$

$\left\{\mathrm{f}: \mathrm{f} \in \mathrm{D}_{<\mathrm{e} \sigma>} \& \forall \mathrm{a}\left[\mathrm{f}(\mathrm{a}) \in[[\beta]]^{\mathrm{w}, \mathrm{g}[\mathrm{a} / \mathrm{i}]}\right]\right\}$

(Kratzer and Shimoyama 2002, 8) 
(84) a. El portero tiene que saludar a cualquier visitante.

'The doorman must greet any visitor.'

b. The doorman must greet any visitor.

Both any and cualquiera are acceptable in the necessity sentences above. Thus, the generalization in (82) predicts that the corresponding indefinite objects (that is, the indefinites in (85) and (86)) will be able to get a generic interpretation.

a. Tienes que contestar una pregunta.

'You must answer a question.'

b. You must answer a question.

a. El portero tiene que saludar a un visitante.

'The doorman must greet a visitor.'

b. The doorman must greet a visitor.

But while this interpretation is possible, it seems harder to obtain than in subject position, and the extent to which it is available varies across speakers. Why should that be, if the mechanism that licenses FC items in necessity sentences is the same that derives generic interpretations for indefinites? While I do not have a fully satisfactory answer to this question, I would like to at least offer some preliminary remarks.

Kratzer (1989/1995) argues that, in English, indefinite objects can only get a generic interpretation if they are able to move covertly to the restriction of the generic operator. ${ }^{25}$ Suppose that, in the absence of a context that makes the generic interpretation salient, speakers prefer to leave the object in situ. If this is the case, the existential interpretation of the object would be preferred out-of-the-blue. A similar argument might be made for Spanish objects.

With plain indefinites, leaving the object in its base position is always a possibility. In contrast, given what I have said so far, in sentences like (83) and (84) the FC item must move to a position where it can combine with the generic operator so as to avoid a fatal contradiction. Since the only possible way of interpreting the FC items in these sentences is to give them a generic reading, we might expect speakers to get this reading effortlessly.

A problem with this line of explanation is that, at least in Spanish, some speakers find it hard to get a generic interpretation for (85) and (86) even when given a suitable context. More research needs to be done in order to establish what factors affect speakers' judgments in these cases.

\subsection{Consequences for possibility sentences}

The proposal in Sect. 2 correctly predicts universal FC items to be licensed in all possibility sentences. As we saw in Sect. 2.3, association with the universal propositional

\footnotetext{
${ }^{25}$ She claims that the objects that can get a generic interpretation in English are the same ones that are able to scramble overtly in German.
} 
operator in possibility sentences does not yield contradictory truth conditions, and therefore it is always an option. While the modification introduced in Sect. 4.1 does not affect this result, it makes further predictions about the interpretation of possibility sentences.

Consider the sentences in (87) below.
a. Un gato puede cazar ratones.
'A cat can hunt mice.'
b. A cat can hunt mice.

In both the Spanish and the English versions, the indefinite subject can get a generic interpretation. Our current hypothesis predicts that a FC item in the same context should be able to associate with the generic operator. The corresponding structure will be assigned (roughly) the interpretation in (89).
a. Cualquier gato puede cazar ratones.
'Any cat can hunt mice.'
b. Any cat can hunt mice.

(89) \{that for every combination of cats $x$, there is an accessible world in which $\mathrm{x}$ hunts mice\}

The upshot of this is that sentences like (88) are predicted to be true in situations where there is no complete freedom of choice. As noted above, if the alternatives introduced by the FC item combine with the generic operator, no propositional alternatives will be generated, so there will be no exclusiveness requirement. In other words, genericity would dilute the freedom of choice component.

There is some initial evidence that this prediction is on the right track. Consider the following scenario (inspired by the documentary The March of the Penguins).

(90) Every year, during the mating season, Emperor Penguins march for 70 miles until they get to the place where they were born, and where they now mate and lay eggs. Crucially, all the penguins march together. This is what they are programmed to do. If a penguin gets lost, the poor thing will not be able to make it on its own.

Suppose that I have just seen the documentary The March of the Penguins. You have heard something about the film on the radio, but you are missing crucial information. We have the following conversation:

(91) You: ¿Sólo los pingüinos jóvenes pueden caminar 70 millas?

'Only the young penguins can walk for 70 miles?'

Me: $\quad$ No, no, cualquier pingüino emperador puede caminar 70 millas.

'No, no, any emperor penguin can walk for 70 miles.' 
Given the scenario above, my reply is true. But if cualquiera could only agree with the propositional quantifier, my reply would be predicted to be false. The sentence in (92) would denote (roughly) the proposition in (93).

(92) Cualquier pingüino puede caminar 70 millas.

'Any penguin can walk 70 miles.'

(93) \{that for every combination of penguins $\mathrm{x}$, there is an accessible world in which only $\mathrm{x}$ marches

And the proposition in (93) is false in the scenario above. Presumably, the only accessible worlds are those in which Emperor Penguins are biologically programmed the way they are in the actual world. And there is no such world in which a lone penguin marches 70 miles on its own.

In contrast, the paraphrase in (94), which corresponds roughly to the generic reading, comes out as true in the given scenario.

(94) \{that for every combination of penguins $x$, there is an accessible world in which $\mathrm{x}$ marches

Thus, the prediction is borne out for the scenario above. Further research is needed to determine whether this prediction holds more generally.

\section{A note on subtrigging}

Above, I have proposed that FC items have two interpretational possibilities:

(i) They can associate with a universal quantifier over propositional alternatives.

(ii) They can associate with the operator responsible for generic readings of indefinites.

This correctly predicts FC items to be ruled out in episodic sentences like (95). We have already seen how option (i) yields contradictory truth conditions for these sentences (Sect. 2.3.3). And option (ii) is of course not viable in these cases, where verbal morphology blocks a generic interpretation.

(95) Juan habló con cualquier mujer.

'John talked-pfv. to any woman.'

However, as first observed by LeGrand (1975) and discussed more recently by Dayal $(1998,2004)$, any can be rescued in simple past sentences by adding a relative clause. This is illustrated by the contrast between (96) and (97) below.

*John talked to any woman. 
This strategy, dubbed 'subtrigging' by LeGrand (1975), does not seem easily available in Spanish, where the result of adding a relative clause to (98) is still marginal, witness (99). ${ }^{26}$

(98) *Juan habló con cualquier mujer.

'Juan talked-pfv. to any woman.'

(99) ?? Juan habló con cualquier mujer que se le acercara.

'Juan talked-pfv. to any woman that came up to him.'

In what follows, I will briefly discuss the possibility that this contrast between the two languages might follow from the differences between their verbal systems.

English simple past tense can have both episodic and generic interpretations. For instance, the example in (100) can be used to describe a particular event (episodic interpretation), or to attribute to the printer the ability of printing documents with graphics (generic dispositional interpretation).

(100) This printer printed documents with graphics.

As shown by (101) below, FC any is licensed in dispositional sentences. ${ }^{27}$ In principle, then, sentences like (100) should license any on their dispositional reading. In the absence of contextual clues, however, the episodic interpretation of simple past sentences seems to be much more salient. Since FC any is ruled out in episodic sentences, sentences like (96) are judged as bad when presented out of the blue. I hypothesize that adding a relative clause to (100), as in (97), somehow facilitates a dispositional reading of the main verb (for reasons yet to be understood). Since any is good in dispositional sentences, this results in acceptability. This way of thinking about English subtrigging fits with an observation by David Dowty and Dick Oehrle reported in Dayal (1998), namely that the sentence Yesterday, John talked to any woman he saw seems “more a statement about John's disposition than about his actual behavior" (Dayal 1998, 454). Of course, for my suggestion to become a full-fledged hypothesis I would need to say exactly how the relative clause helps the dispositional interpretation. I will have to leave this issue open for now.

(101) This printer prints any document.

\footnotetext{
26 This is at odds with Quer's judgment for the corresponding Catalan sentences (Quer 1998, 2000).

27 Elsewhere (Menéndez-Benito 2005), I have argued (building on Dahl 1975) that dispositional sentences should be analyzed as possibility sentences and therefore the fact that they license FC items is unproblematic.
} 
In Spanish, the generic/episodic distinction in the past is marked by aspectual morphology: in generic sentences, the verb bears imperfective morphology; in episodic sentences, perfective morphology. For instance, while the imperfective sentence in (102) can mean that (at some contextually relevant past time) this printer had the capacity of printing documents with graphics (dispositional interpretation), the perfective sentence in (103) means that there was at least one episode in which the printer printed documents with graphics.

(102) Esta impresora imprimía documentos con gráficos.

'This printer printed-impf. documents with graphics.'

(103) Esta impresora imprimió documentos con gráficos.

'This printer printed-pfv. documents with graphics.'

Hence, if the role of subtrigging is to facilitate a generic reading of the main verb, we expect this strategy to be blocked in Spanish. That is, cualquiera should be bad in perfective sentences regardless of whether or not it is modified by a relative clause. The results of an acceptability rating questionnaire reported in MenéndezBenito (2005) suggest that this is indeed the case. ${ }^{28}$ In this study, perfective sentences like (104) were judged as worse than imperfective sentences like (105), despite the fact that cualquiera is modified by a relative clause in both cases.

(104) Mi primo Juan coqueteó con cualquier mujer que le sonriera con amabilidad.

'My cousin Juan flirted-pfv. with any woman that smiled at him kindly.'

(105) Mi primo Juan coqueteaba con cualquier mujer que le sonriera con amabilidad.

'My cousin Juan flirted-impf. with any woman that smiled at him kindly.'

Additionally, the experimental results reported in Menéndez-Benito (2005) can be taken to suggest that episodic sentences with cualquiera are better when the events they describe can be easily understood as being the result of a policy or rule (as in (106)) than when they cannot (107).

(106) La policía detuvo a cualquier persona que apoyara al antiguo gobierno públicamente.

'The police arrested-pfv. any person that publicly supported the previous government.'

(107) Mi primo Juan coqueteó con cualquier mujer que le sonriera con amabilidad.

'My cousin Juan flirted-pfv. with any woman that smiled at him kindly.'

\footnotetext{
${ }_{28}$ See Menéndez-Benito (2005) for a detailed presentation of the experiment, including the full list of experimental items.
} 
While the results are not conclusive (see Menéndez-Benito 2005 for discussion), they open up the interesting possibility that perceivers can to some extent 'mimic' the effect of generic morphology by non-grammatical means and thereby partially rescue cualquiera in episodic (i.e. perfective) contexts.

If the observed difference between English and Spanish is to be explained along the lines suggested above, we will expect subtrigging to work only in languages where the episodic/generic distinction is not overtly marked. This, however, does not seem to be the case in view of the Italian data reported in Chierchia (2006) and Aloni (2007b). Italian behaves like Spanish in that the episodic/generic distinction is marked by aspectual morphology. But, according to Aloni (2007b), the Italian FC items qualsiasi and qualunque are good in episodic sentences when modified by a relative clause, but bad when unmodified (on qualsiasi, see also Chierchia 2006). She gives the following examples:

(108) \#Qualsiasi/qualunque donna cadde.

'Any woman fell.'

(109) Qualsiasi/qualunque donna che provò a saltare cadde

'Any woman who tried to jump fell.'

One possibility is that qualsiasi is just not amenable to the proposal presented here. The Italian data could then be accounted for by the proposal of Aloni (2007b), who follows Menéndez-Benito (2005) in assuming that FC items are universal indeterminate pronouns, but claims that these items trigger an operation of exhaustification more general than the one assumed there. On Aloni's account, the semantic composition delivers universal quantification over mutually exclusive propositions in the case of ungrammatical sentences like (108), just as in the account presented here. In contrast, for subtrigged sentences like (109), her proposal derives universal quantification over a set of compatible propositions. In particular, (109) will be true if all the propositions in $\{\mathrm{a}$ fell, $\mathrm{b}$ fell, $\mathrm{c}$ fell... $\}$-where $\mathrm{a}, \mathrm{b}, \mathrm{c}, \ldots$ are all the women that tried to jump - are true. That is, (109) will be interpreted as 'Every woman that tried to jump fell'. Under this account, the Italian judgments would be explained, but we would then need an explanation for why subtrigging is not fully available in Spanish. ${ }^{29}$

Before we conclude that Italian and Spanish are radically different with respect to subtrigging, a note of caution is in order. While experimental evidence shows that subtrigged sentences are not completely acceptable in Spanish, Menéndez-Benito (2005) suggests that partial repairs might be available. If this suggestion is on the right track, we might expect gradient judgments and variability across speakers. Hence, in order to determine the status of subtrigging in Italian, it may be necessary to gather data experimentally, controlling for factors that could affect the

\footnotetext{
29 The reader is referred to Aloni's work for the details of her proposal. For another recent account of subtrigging, see Jayez and Tovena (2007).
} 
acceptability of subtrigged sentences. This is a task that I will have to leave for further research.

\section{Concluding remarks and issues for further research}

Back in 1967, Zeno Vendler noted that an essential feature of items like any was their ability to convey freedom of choice. The starting point for the analysis I have proposed here is the observation that wide scope universal quantification is not enough to capture this freedom of choice component. To guarantee Free Choice, we must add an exclusiveness condition to the standard universal paraphrases. I have argued that this idea can be very naturally implemented in Kratzer and Shimoyama's Hamblin semantics, by claiming that (i) FC items of the any-type are universal indeterminate pronouns (they have to agree with a universal quantifier) and (ii) the propositional alternatives they generate are mapped into a set of mutually exclusive propositions. As we have seen, the interaction of these two components yields the desired FC effect.

The basic proposal that derives the FC effect in possibility sentences goes a long way toward deriving the puzzling distribution of universal FC items: it automatically rules out episodic sentences like *You took any of these cards, necessity sentences like *You must take any of these cards, and configurations where the universal quantifier has narrow scope with respect to a possibility modal. The acceptability of necessity sentences like Any student must work hard will also be accounted for if FC items can associate with the generic operator, construed as a universal quantifier over individual alternatives.

Many questions remain, of course. My tentative discussion of subtrigging, in particular, raises a number of issues. First of all, for my suggestion about the English-Spanish contrast to be seriously entertained, it would have to be supplemented with an explanation of why relative clauses might facilitate the dispositional reading. Second, following Menéndez-Benito (2005), I have briefly noted that, in Spanish, some subtrigged sentences seem to be better than others, the relevant factor being whether the events described can be easily understood as the result of a policy or rule. The nature and degree of availability of this type of partial repair needs to be investigated further. Finally, we need to probe into the crosslinguistic status of subtrigging - to what extent and under which conditions do different languages allow this strategy?

Another question concerns adverbs like maybe and perhaps. While these adverbs seem to convey existential quantification over worlds, they do not license universal FC items. The contrast between existential modal adverbs and existential modal auxiliaries is illustrated in $(110) .^{30}$

\footnotetext{
30 Thanks to Jonathan Schaffer, Nathan Klinedinst, and an anonymous reviewer for (independently) pointing out this problem to me.
} 
(110) a. \#Maybe/perhaps John took any of the cards from this deck.

b. John can take any of the cards from this deck.

How can we account for the ungrammaticality of (110) within the limits of the proposal I have put forward? While I do not have an answer to this question, I would like to briefly sketch a couple of potential ways to go.

As noted in Sect. 2, the analysis I have presented here predicts that only existentials that allow alternatives to project up the tree will rescue universal FC items. Thus, one possibility would be to try to argue that the scope of modal adverbs is closed by an existential propositional operator. As noted before, this would create an intervention effect, which would lead to ungrammaticality. Further research would of course be needed to determine whether this possibility is at all viable.

Alternatively, one could assume that, unlike modal auxiliaries, modal adverbs are forced to appear above the $\forall$ operator, as in (111).

\section{(111) [maybe [ $\forall$ [Excl [John took any of these cards]]]]}

As we saw in Sect. 3, this LF would be assigned contradictory truth conditions (since the complement of the modal element denotes the contradictory proposition), which would render the corresponding sentence ungrammatical. Of course, pursuing this line would amount to abandoning the claim that the universal quantifier can freely be inserted up to interpretability and would therefore require us to investigate more closely what the distributional properties of this quantifier are.

A more general question is how the analysis put forward here fares when applied to other constructions involving FC items, such as conditionals, imperatives, or comparatives. I hope to be able to address this question in future work.

Acknowledgments This article reports some of the results of my dissertation (Menéndez-Benito 2005). I would like to thank my committee members, Angelika Kratzer, Lyn Frazier, Rajesh Bhatt, and Jonathan Schaffer for their invaluable help. Special thanks to my advisor, Angelika Kratzer, for innumerable conversations, much excellent advice, and constant encouragement throughout the dissertation year and beyond. Thanks also to Luis Alonso-Ovalle, Jan Anderssen, Ana Arregui, Sandy Chung, Donka Farkas, Danny Fox, Barbara Partee, Chris Potts, Kyle Rawlins, Florian Schwarz, and Anne-Michelle Tessier for very helpful discussions. I am also very grateful to two anonymous $N A L S$ reviewers for their detailed comments and suggestions, which greatly improved the final version of this paper. For challenging questions and useful suggestions, I would like to thank the students in my 2005 Free Choice seminar at UC Santa Cruz, as well as audiences at UMass Amherst, UC Santa Cruz, the 2005 LSA Summer Institute, Sinn und Bedeutung 10, NELS 36, UC San Diego, the University of Maryland, MIT, the University of Rochester, and Stanford University. I would also like to thank Christine Bartels for her editorial help. Of course, all errors are my own.

Open Access This article is distributed under the terms of the Creative Commons Attribution Noncommercial License which permits any noncommercial use, distribution, and reproduction in any medium, provided the original author(s) and source are credited.

\section{References}

Abrusán, Márta. 2007a. Even and Free Choice any in Hungarian. In Proceedings of Sinn und Bedeutung 11, ed. E. Puig-Waldmüller, 1-15. Barcelona: Universitat Pompeu Fabra. 
Abrusán, Márta. 2007b. Contradiction and grammar: The case of weak islands. PhD diss., MIT (revised version, May 2008).

Abrusán, Márta. 2008. Islands of contradiction: presuppositional and negative islands. In Proceedings of SALT 18, ed. T. Friedman and S. Ito, 1-18. Ithaca, N.Y.: Cornell University.

Aloni, Maria 2003. Free choice in modal contexts. In Proceedings of Sinn und Bedeutung 7 (Arbeitspapier Nr.114 des Fachbereichs Sprachwissenschaft), ed. M. Weisgerber, 25-37. University of Konstanz. http://ling.uni-konstanz.de/pages/conferences/sub7/.

Aloni, Maria. 2007a. Free Choice, modals and imperatives. Natural Language Semantics 15: 65-94

Aloni, Maria 2007b. Free Choice and exhaustification: An account of subtrigging effects. In Proceedings of Sinn und Bedeutung 11, ed. E. Puig-Waldmüller, 16-30. Barcelona: Universitat Pompeu Fabra.

Aloni, M., and R. van Rooij. 2007. Free Choice items and alternatives. In Proceedings of the KNAW Academy Colloquium: Cognitive foundations of interpretation, ed. G. Bouma et al., 5-26. Amsterdam: Royal Netherlands Academy of Arts and Sciences.

Arregui, Ana. 2006. Cualquier, exception phrases and negation. In Romance languages and linguistic theory 2004, ed. Jenny Doetjes and Paz González, 1-22; Amsterdam: Benjamins.

Barwise, John, and Robin Cooper. 1981. Generalized quantifiers and natural language. Linguistics and Philosophy 4, 159-219.

Bonomi, Andrea. 1997. Aspect, quantification and when-clauses in Italian. Linguistics and Philosophy 20: 469-514.

Chierchia, Gennaro. 1984. Topics in the syntax and semantics of infinitives and gerunds. PhD diss., University of Massachusetts at Amherst.

Chierchia, Gennaro. 2006. Broaden your views: Implicatures of domain widening and the "logicality of language”. Linguistic Inquiry 37 (4): 535-590.

Dahl, Osten. 1975. On generics. In Formal semantics of natural language, ed. E. Keenan, 99-112. Cambridge: Cambridge University Press.

Dayal, Veneeta. 1998. Any as inherently modal. Linguistics and Philosophy 21: 433-76.

Dayal, Veneeta. 2004. The universal force of Free Choice Any. Linguistic Variation Yearbook 4: 5-40.

Dowty, David R. 1979. Word meaning and Montague grammar, Vol. 7. Dordrecht: Kluwer.

Farkas, Donka. 2006. Free Choice in Romanian. In Drawing the boundaries of meaning, neo-Gricean studies in pragmatics and semantics in honor of Laurence R. Horn. ed. Betty J. Birner and Gregory Ward, 71-94. Amsterdam: Benjamins.

Fox, Danny. 2002. Antecedent-contained deletion and the copy theory of movement. Linguistic Inquiry 33: 63-96.

Fox, Danny. 2006. Free choice disjunction and the theory of scalar implicature. Ms., MIT.

Fox, Danny, and Martin Hackl. 2006. The universal density of measurement. Linguistics and Philosophy 29: 537-586.

Gajewski, Jon. 2002. L-analyticity in natural language. Ms., MIT.

Gajewski, Jon. 2008a. More on quantifiers in comparative clauses. In Proceedings of SALT 18, 340-357. Ithaca, N.Y.: CLC Publications.

Gajewski, Jon. 2008b. NPI any and connected exceptive phrases. Natural Language Semantics 16 (1): 69-110.

Gajewski, Jon 2009. L-triviality and grammar. Handout of a talk delivered at the UConn Logic Group, February 27, 2009.

Giannakidou, Anastasia. 2001. The meaning of Free Choice. Linguistics and Philosophy 24: 659-735.

Giannakidou, Anastasia, and Lisa Lai-Shen Cheng. 2006. (In)definiteness, polarity and the role of wh-morphology in Free Choice. Journal of Semantics 23: 135-186.

Groenendijk, J., and M. Stokhof. 1984. Studies on the semantics of questions and the pragmatics of answers. PhD diss., University of Amsterdam.

Hamblin, Charles. 1973. Questions in Montague grammar. Foundations of Language 10: 41-53.

Haspelmath, Martin. 1997. Indefinite pronouns. Oxford: Oxford University Press.

Heim, Irene. 1982. The semantics of definite and indefinite Noun Phrases. PhD diss., University of Massachusetts at Amherst.

Heim, Irene, and Angelika Kratzer. 1998. Semantics in generative grammar. Malden, MA.: Blackwell.

Horn, Larry. 2005. Airport '86 revisited: Toward a unified indefinite any. In Reference and quantification: The Partee effect, ed. G.N. Carlson and F.J. Pelletier, 179-205. Stanford, CA: CSLI Publications.

Horn, Laurence. 2000. ANY and EVER: Free choice and free relatives. IATL 15: 71-111.

Jayez, J., and L. Tovena. 2005. Free-choiceness and non individuation. Linguistics and Philosophy 28: 1-71. 
Jayez, J., and L. Tovena. 2007. Subtrigging as alternatives through regularities. In Proceedings of the Sixteenth Amsterdam Colloquium 127-132.

Kadmon, Nirit, and Fred Landman. 1993. Any. Linguistics and Philosophy 16: 353-422.

Kratzer, Angelika. 1989/1995. Stage-level and individual-level predicates. In The generic book, ed. Gregory N. Carlson and Francis Jeffrey Pelletier, 125-175. Chicago: The University of Chicago Press.

Kratzer, Angelika. 2005. Indefinites and the operators they depend on: From Japanese to Salish. In Reference and quantification: The Partee effect, ed., G. N. Carlson and F.J. Pelletier, 113-142. Stanford, CA: CSLI Publications.

Kratzer, Angelika, and Junko Shimoyama. 2002. Indeterminate phrases: The view from Japanese. http:// semanticsarchive.net/Archive/WEwNjc4Z/. Slightly shorter version in The Proceedings of the Third Tokyo Conference on Psycholinguistics, ed. Yokio Otsu, 1-25. Tokyo: Hituzi Syobo.

Krifka, Manfred, Francis Jeffrey Pelletier, Greg N. Carlson, Alice ter Meulen, Gennaro Chierchia, and Godehard Link. 1995. The generic book. Chicago: The University of Chicago Press.

Lee, Youngjoo. 2005. Exhaustivity as agreement: The case of Korean man 'only'. Natural Language Semantics 13: 169-200.

LeGrand, J. 1975. Or and any: The syntax and semantics of two logical operators. PhD diss., The University of Chicago.

Link, Godehard. 1983. The logical analysis to plurals and mass terms: A lattice-theoretical approach. In Meaning, use, and interpretation of language, ed. R. Bäuerle et al., 302-323. Berlin: de Gruyter.

Link, Godehard. 1991. Plural. In Semantik: Ein internationales Handbuch der zeitgenössischen Forschung, ed., A. von Stechow, and D. Wunderlich 418-440. Berlin: de Gruyter.

Menéndez-Benito, Paula. 2005. The grammar of choice, PhD diss., University of Massachusetts at Amherst.

Quer, Josep. 1998. Mood at the interface. PhD diss., Utrecht University.

Quer, Josep. 2000. Licensing free choice items in hostile environments: The role of aspect and mood. SKY Journal of Linguistics 13: 251-268.

Sæbø, Kjell Johan. 2001. The semantics of Scandinavian free choice items. Linguistics and Philosophy 24: 737-787.

Simons, Mandy. 2005. Dividing things up: The semantics of or and the modal/or interaction. Natural Language Semantics 13: 271-316.

Van Benthem, J.F.A.K. (1989). Logical constants across types. Nature Dame Journal of Formal Logic 20: 469-514.

Vendler, Zeno. 1967. Linguistics in philosophy. Ithaca, NY: Cornell University Press.

von Fintel, Kai. 1993. Exceptive constructions. Natural Language Semantics 1: 123-148.

Zimmermann, Thomas Ede. 2001. Free choice disjunction and epistemic possibility. Natural Language Semantics 8: 255-290. 